\title{
In Reply to Gürdoğan and Altay
}

\author{
Marina Ruxandra Otelea1, Adrian Streinu-Cercel1,2, Cristian Băicus1,3, Maria Nitescu1,2 \\ ${ }^{1}$ Carol Davila University of Medicine and Pharmacy, Bucharest, Romania \\ ${ }^{2}$ Institute for Infectious Diseases 'Matei Bals', Bucharest, Romania \\ ${ }^{3}$ Clinical Hospital Colentina, Bucharest, Romania
}

To the Editor,

We would like to thank you for this letter that gives us an opportunity to further comment on the results of our study (1).

In the article, we emphasized the importance of the adipokine profile, as a whole and not a single biomarker, as the main conclusion of our research. In view of the present data, the leptin to adiponectin ratio is a strong and affordable candidate, but we cannot disregard the potential of the large number of adipokines secreted by unhealthy adipocytes to be better markers. Moreover, we are aware that gender differences have been reported with respect to adipokine secretion; therefore, the correlations that we reported were checked for gender influence. The correlation was maintained, regardless of gender.

However, this does not mean that the individual components, i.e., the leptin and adiponectin plasma values, did not differ between men and women in our study. In accordance to the article cited by Dr. Gürdogan and Dr. Altay, we found both leptin and adiponectin to be significantly higher in women than that in men (2). However, contrary to the previously mentioned study (1), the leptin to adiponectin ratio was similar in both the sexes (Kruskal-Wallis, ANOVA, $\mathrm{p}=0.845, \mathrm{H}=0.038$ ). Similarly, no significant gender differences were reported by other authors with respect to the leptin to adiponectin ratio and the incidence of the metabolic syndrome (3) in cross sectional studies.

The different reference values in women and men are probably justified by the hormonal secretions and distribution of visceral versus subcutaneous fat $(4,5)$. In prospective studies, this difference leads to gender-specific cut-offs of the leptin to adiponectin ratio for the prediction of risk (6) as well as prediction of the regression of the metabolic syndrome in high-risk individuals (7). Our study was not a longitudinal one and did not analyze such differences; however, if it would have been, the sex difference in the adipokine profile would have been a part of the analysis.

There are definitely more questions to be answered about the best biomarker profile of the unhealthy adipose tissue (8), and we agree that distinguishing the gender and age categories will better stratify the risk.

\section{REFERENCES}

1. Otelea MR, Streinu-Cercel A, Băicus C, Nitescu M. The Adipokine Profile and the Cardiometabolic Risk in Non-Obese Young Adults. Balkan Med J 2019;36:155-61.

2. Falahi E, Khalkhali Rad AH, Roosta S. What is the best biomarker for metabolic syndrome diagnosis? Diabetes Metab Syndr 2015;9:366-72.

3. Selthofer-Relatić K, Radić R, Stupin A, Šišljagić V, Bošnjak I, Bulj N, et al. Leptin/ adiponectin ratio in overweight patients - gender differences. Diab Vasc Dis Res 2018; $15: 260-62$.

4. Frühbeck G, Catalán V, Rodríguez A, Ramírez B, Becerril S, Salvador J, et al. Adiponectin-leptin Ratio is a Functional Biomarker of Adipose Tissue Inflammation. Nutrients 2019;11. pii: E454.

5. Hellström L, Wahrenberg H, Hruska K, Reynisdottir S, Arner P. Mechanisms behind gender differences in circulating leptin levels. J Intern Med 2000;247:457-62.

6. Moon HU, Ha KH, Han SJ, Kim HJ, Kim DJ. The Association of Adiponectin and Visceral Fat with Insulin Resistance and $\beta$-Cell Dysfunction. J Korean Med Sci 2018;34:e7.

7. Li G, Xu L, Zhao Y, Li L, Fu J, Zhang Q, et al. Leptin-adiponectin imbalance as a marker of metabolic syndrome among Chinese children and adolescents: The BCAMS study. PLoS One 2017;12:e0186222.

8. Kang DR, Yadav D, Koh SB, Kim JY, Ahn SV. Impact of Serum Leptin to Adiponectin Ratio on Regression of Metabolic Syndrome in High-Risk Individuals: The ARIRANG Study. Yonsei Med J 2017;58:339-46.

9. Zachariah JP, Quiroz R, Nelson KP, Teng Z, Keaney JF, Sullivan LM, et al. Prospective Relation of Circulating Adipokines to Incident Metabolic Syndrome: The Framingham Heart Study. J Am Heart Assoc 2017;6. pii: e004974. 